\title{
Teratogen Update: Angiotensin-Converting Enzyme Inhibitors
}

\author{
MASON BARR, JR. \\ Departments of Pediatrics, Pathology, and Obstetrics and Gynecology, University of Michigan, \\ Ann Arbor, Michigan 48109
}

\begin{abstract}
Angiotensin-converting enzyme (ACE) inhibitors (ACEI) were developed from a serendipitous discovery that a Brazilian snake venom contained a bradykininpotentiating factor with vasodilating properties (Ferreira, '65). The physiological significance of this was established by demonstrating inhibition of ACE by the peptide mixture from the snake venom (Bakhle, '68). The first clinically usable ACEI, captopril, was synthesized in 1975 (Cushman and Ondetti, '91). In the United States, captopril (Capoten ${ }^{(\mathbb{B})}$ ) was approved for clinical use in 1981, followed by enalapril (Vasotec ${ }^{(5)}$ in 1985, lisinopril (Prinivil ${ }^{\mathbb{W}}$, Zestril ${ }^{\mathbb{E}}$ ) in 1987 , benazepril (Lotensin ${ }^{\circledR}$ ), fosinopril (Monopril ${ }^{\circledR}$ ), and ramipril (Altace $^{(\mathbb{E})}$ in 1991, and quinapril (Accupril ${ }^{\circledR}$ ) in 1992. Other ACEIs discussed in the literature but not currently marketed in the United States include abutapril, alacepril, ceronapril, cilazepril, delapril, idrapril, imidapril, moexipril, pentopril, perindopril, rentiapril, spirapril, temocapril, trandolapril, zabicipril, and zofenapril.
\end{abstract}

Two of the currently available ACEIs, captopril and lisinopril, are in the active form; the others are proactive drugs that are deesterified in the liver to the active form (designated by the suffix -prat) and were developed to enhance absorption or prolong activity or both. Captopril binds the enzyme by means of a sulfhydryl group, fosinopril by a phosphodyl group, and the others by a carboxyl (Materson and Preston, '94). ACEIs are mainly excreted through the kidney, although up to $50 \%$ of ramipril and fosinopril is excreted in the feces (Williams, '88; manufacturers' literature).

Placental passage of the various ACEIs appears to be both species and drug dependent. In common laboratory animals there may be little passage of some ACEIs through the placenta (Endo et al., '92). However, in humans it is established from measurements in exposed newborns that enalapril, captopril, and lisinopril do cross the placenta in pharmacologically significant amounts, and it is assumed that the other available ACEIs also cross the human placenta (Schubiger et al., '88; Pryde et al., '93). Once in the fetus, it may be presumed that an ACEI will be renally excreted (provided there is urine production) largely as the active drug, which may then be swallowed and recirculated. What import such drug recirculation might have on fetal physiology has not been assessed.

\section{USE OF ACEIs}

Since their introduction, ACEIs have come to be regarded as a major advance in the treatment of hypertension (Thurston, '92; Rodicio and Ruilope, '93; Materson and Preston, '94). It has been observed that most types of hypertension respond favorably to ACEI therapy, with or without the addition of diuretics (Sassano et al., '87; Garay et al., '94). Antihypertensives such as beta-adrenergic receptor blockers and diuretics tend to increase peripheral resistance and have side effects on the metabolism of electrolytes, glucose, and lipids. In contrast, ACEIs decrease vascular resistance, improve glucose handling, control left ventricular mass, and offer a degree of myocardial protection (Williams, '88; Gavras, '88; Materson and Preston, '94). In the absence of heart failure, ACEIs produce little change in heart rate, cardiac output, or pulmonary wedge pressure in normal or hypertensive people (Vidt et al., '82; Todd and Heel, '86; Gomez et al., '87). They have also been found to contribute to an improved quality of life for the hypertensive patient, particularly when compared to beta-blockers (Materson and Preston, '94).

A use for ACEIs that has excited considerable interest stems from the demonstration that they impede the progression of nephropathy associated with diabetes mellitus, both type 1 and type 2 (Ravid et al., '93; Bakris, '93; Viberti et al., '94). The ACEIs reduce microalbuminuria, preserve renal function, and increase insulin sensitivity; these effects are believed to be independent of the antihypertensive action of these drugs (Ravid et al., '93).

Guthrie ('93) reported that prescriptions for ACEIs increased nearly $250 \%$ between 1986 and 1990 , testifying to their popularity in clinical use, and many articles have appeared extolling their use as first line agents in the treatment of hypertension. The use of

Received October 3, 1994; accepted October 3, 1994.

Address reprint requests to Mason Barr, Jr., M.D., Pediatric Genetics-Teratology Unit, D1109 MPB 0718, University of Michigan Medical Center, Ann Arbor, MI 48109-0718. 
ACEIs for myocardial protection poses little concern to the teratologist, since the vast majority of such use will be in patients beyond the childbearing years. However, their use for mild or essential hypertension, and in such conditions as the autoimmune diseases and diabetes mellitus, could expose a considerable number of women in the childbearing years, not a few of whom will be pregnant. The use of ACEIs for the management of pregnancy-induced hypertension, by definition, creates a certain and identifiable fetal exposure. The actual number of pregnancies exposed to ACEIs cannot be determined from available data. Piper et al. ('92) reported that of 106,813 Tennessee Medicaid patients who delivered a live or stillborn infant during 1983-1988, 19 were exposed to an ACEI. Given the expansion of use of these agents to the current time, it would be reasonable to expect that the number of fetal exposures will increase.

\section{ADVERSE EFFECTS}

In the enthusiasm to employ ACEIs as first line agents for treatment of hypertension and to retard development of diabetic nephropathy, their safety sometimes seems to be overstated. As wonderful as they seem, ACEIs are not without adverse effects. As described below, because they suppress aldosterone secretion, they are liable to produce hyperkalemia, particularly in the face of sodium restriction, heart failure, diabetes, and coadministration of potassium-sparing diuretics and nonsteroidal anti-inflammatory drugs (Williams, '88; Schlueter et al., '94). Their use in certain circumstances, such as bilateral renal artery stenosis, can contribute to, not ameliorate, renal dysfunction (Hricik et al., '83; Cooke and Debesse, '94). In some cases the dysfunction may be reversible (Wood et al., '91) and in others irreversible (Devoy et al., '92). Perhaps the most common side effect of the ACEIs is an irritating cough, which ironically has generated more literature than has the possibility of fetal damage.

As early as 1980, there were reports of fetal wastage in ACEI-exposed experimental animals (BroughtonPipkin et al., '80, '82; Ferris and Weir, '82). In 1981, the first adverse outcome in a human pregnancy was reported (Duminy and Burger, ' 81 ). This was followed in short order by other cases implicating both captopril and enalapril as potential fetotoxins (Guignard, '82; Boutroy et al., '84; Caraman et al., '84; Fiocchi et al., '84; Rothberg and Lorenz, '84). Warnings about the use of ACEIs in human pregnancy appeared in the literature as early as 1985 (Lindheimer and Katz, '85). On the other hand, some recent reviews of the ACEIs make no mention of the possibility of adverse fetal effects (Materson and Preston, '94; Pinkney and Yudkin, '94). Pryde et al. ('93) recently proposed the designation "ACE inhibitor fetopathy," summarized 29 affected cases from the literature, and added 3 more. Two more cases have been reported since the review by Pryde et al. (Piper et al., '92'; Thorpe-Beeston et al., '93), and I have received at least partial reports of five others from medical colleagues and attorneys. It appears that the bulk of ACEI fetopathy cases have ensued after enalapril exposure, but cases associated with captopril and lisinopril are recorded (Hanssens et al., '91; Pryde et al., '93). As pointed out by Brent and Beckman ('91), there is no reason to assume that the other ACEIs are incapable of producing the same result. Similarly, many of the cases have involved coexposure to other antihypertensive agents, and while combination therapy may pose more risk to the fetus, monotherapy with an ACEI has produced the full-blown fetopathy.

The most commonly reported adverse effect of ACEI exposure of the fetus is that of second to third trimester onset of oligohydramnios and growth restriction, followed by delivery of an infant whose neonatal course is complicated by prolonged and often profound hypotension and anuria (Rosa et al., '89). The presentation may also include the oligohydramnios deformation sequence and its lethal component, pulmonary hypoplasia (Guignard et al., ' 81 ; Mehta and Modi, '89; Cunniff et al., '90; Pryde et al., '93). Although studies of the histology of the kidneys in ACEI-exposed fetuses and infants are few in number, they are consistent in their demonstration of renal tubular dysgenesis (Knott et al., '89; Cunniff et al., '90; Pryde et al., '93). Delayed development of the calvaria has been noted in enough cases to consider it a part of the syndrome. Postnatal persistence of a patent ductus arteriosus (PDA) has also been suggested to be part of the syndrome, but it is hard to determine if this finding is an effect of ACEI exposure.

The true rates of adverse fetal effects from ACEI use in human pregnancy cannot be determined from available information. Certainly, a number of exposed pregnancies have resulted in no measurable adverse effect (Ducret et al., '85; Kreft-Jais et al., '88; Piper et al., '92). In the largest published series there were 31 pregnancies exposed either to captopril $(n=22)$ or enalapril $(\mathrm{n}=9$ ) (Kreft-Jais et al., ' 88 ). The reported adverse outcomes included nine cases of intrauterine growth restriction, three intrauterine deaths, and two infants with PDA, of which one ultimately required ligation. The 22 other cases in this report were presumably unaffected.

The adverse developmental effects of ACEIs are purposely designated ACEI fetopathy because as yet there is no convincing evidence that they cause harm in the first trimester of human gestation or its equivalent in laboratory animals. Studies with captopril and enalapril in rats failed to show malformations resulting from

${ }^{1}$ One case described by Piper et al. ('92), with microcephaly and encephalocele, was classified as an example of hypocalvaria: I believe this infant's problems were probably unrelated to ACEI exposure. 
high doses (Fujii et al., '85; Fujii and Nakatsuka, '85; Robertson et al., '86; Al-Shabanah et al., '91; Al-Harbi et al., '92), although at the highest doses tested, fetal growth restriction, delayed ossification, and resorptions were noted in conjunction with evidence of maternal toxicity. In humans, the case reported by Thorpe-Beeston et al. ('93) was found to have renal cystic dysplasia, a disorder distinct from the renal tubular dysgenesis found in other cases, but still likely to be a fetal rather than an embryonic effect. In the case reported by Duminy and Burger ('81) there was a terminal transverse deficiency of a limb, again likely to be of fetal origin. The second case mentioned by Piper et al. ('92) was remarkable for microcephaly and encephalocele, the latter almost certainly a problem of first trimester origin, and I am aware of an enalapril exposure-associated case of anencephaly. These few disparate anomalies associated with ACEI exposure do not constitute sufficient evidence of true teratogenicity, although admittedly there is insufficient evidence to be confident of safety in the first trimester. Currently, the recommendation is to offer reassurance of unlikely first trimester effects, but to avoid second and third trimester exposure, unless absolutely necessary for the mother's well being.

\section{REVIEW OF RENIN-ANGIOTENSIN SYSTEM (RAS)}

Angiotensin I is a decapeptide formed from the action of renin on its precursor, angiotensinogen (Fig. 1). Angiotensin I has no known biological action in humans but is rapidly converted to the biologically active octapeptide, angiotensin II. This conversion is effected by ACE, a zinc metalloprotease that catalyzes the hydrolysis of carboxy-terminal dipeptides from oligopeptide substrates. The principal substrates are angioten$\sin I$ and the nonapeptide, bradykinin, but other substrates are affected as well (Ehlers and Riordan, '89). Angiotensin II is a potent vasoconstrictor, stimulates aldosterone secretion from the adrenal cortex, and suppresses renin release by increasing sodium retention, whereby it closes a negative-feedback loop. A parallel system involves the formation of bradykinin and its inactivation by kininase II (which is identical with ACE). Angiotensin II raises blood pressure, and bradykinin, if not inactivated by the enzyme, lowers blood pressure.

ACE has two catalytic sites, one near the carboxyl terminus and one near the amino acid terminus. These sites may have specific substrates, but angiotensin I and bradykinin appear to be catalyzed equally at both sites (Johnston et al., '93). The ACE gene is developmentally regulated in a tissue-specific manner and plays a role in the regulation of renal function and growth (Yosipiv et al., '94). The ACE gene exhibits polymorphism, marked by the insertion or deletion of a $250 \mathrm{bp}$ fragment in intron 16 of the gene (Rigat et al.,

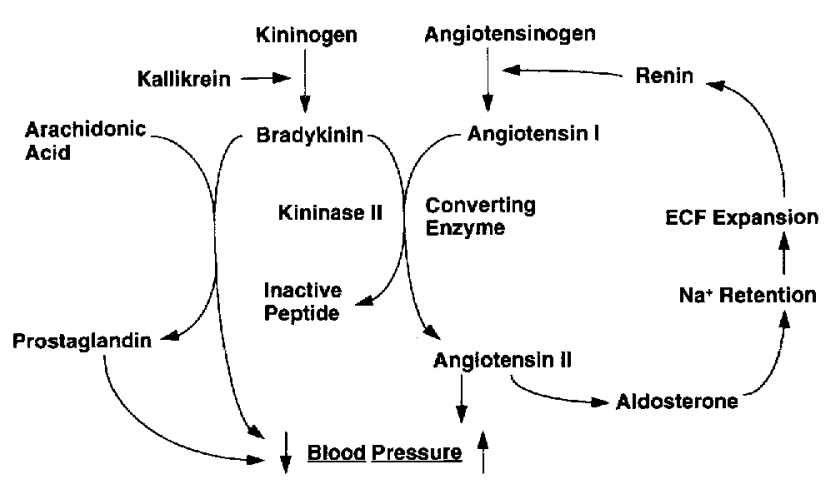

Fig. 1. Schematic representation of the renin-angiotensin-bradykinin system. ECF = extracellular fluid.

'90). Homozygotes for the deletion (DD) show the highest serum levels of ACE activity, while homozygotes for the insertion (II) have the lowest levels. The prevalence of the gene types varies in different populations (Lee, '94), and it has been reported that the deletion genotype is less prevalent in diabetic patients with nephropathy than in those without nephropathy (Marre et al., '94). Angiotensin II receptors similarly have two types: type $1\left(\mathrm{AT}_{1}\right)$ is found in a wide variety of tissues in the adult and seems to mediate all the known effects on angiotensin II related to the RAS. This type of receptor has two subtypes, $\mathrm{AT}_{1 \mathrm{~A}}$ and $\mathrm{AT}_{1 \mathrm{~B}}$, which are said to show few pharmacological differences and may function as growth factors. While the type $2\left(\mathrm{AT}_{2}\right)$ receptor is the predominant type found in the gestational day (GD) 19 rat fetus, fetal adrenal cortex and renal glomeruli express both $\mathrm{AT}_{1 \mathrm{~A}}$ and $\mathrm{AT}_{1 \mathrm{~B}}$ mRNAs (Grone et al., '92; Shanmugam et al., '94). Their roles in fetal development are being investigated. What effect such genetic diversity, in mother or fetus, may have on the occurrence of adverse fetal effects from ACEI exposure is unknown at this time, but should be explored.

The RAS becomes crucially important under conditions of low renal perfusion pressure (Hall et al., '77; Blythe, '83). In these conditions, which pertain to the fetus, angiotensin II-mediated efferent arteriolar resistance is essential to the maintenance of glomerular filtration (GFR) and production of urine (Rudolph et al., '71; Giugnard, '82). Activation of bradykinin by suppression of angiotensin II can compromise GFR by virtue of bradykinin's vasodilatory effect on the efferent arteriole (Kon et al., '93). In the adult, ACEIs increase renal blood flow. Usually this occurs without modifying the GFR because vasodilation of efferent arterioles exceeds that of the afferent arterioles (Williams, '88). In cases of renal artery stenosis, bilateral or unilateral in a solitary kidney, there is an inability to increase renal blood flow sufficiently to compensate for the efferent arteriolar dilation and maintain glomerular perfusion pressure (Hricik et al., '83).

In pregnancy-induced hypertension mean arterial blood pressure is correlated with serum ACE activity 
(Li et al., '92) and is characterized by enhanced angiotensin II sensitivity due to an increase in angiotensin II receptor number (Graves et al., '92). However, the RAS is known to be both a circulating and a tissue hormonal system, and, of the two, tissue systems may be the more important (Ehlers and Riordan, '89; Johnston et al., '92). ACE is widely distributed in the body; it has been found in soluble form in body fluids and in membrane-bound form in arterial endothelial cells within and outside the pulmonary circulation, in epithelial cells with brush borders (placenta, kidney, intestine, and choroid plexus), in neuroepithelial cells, and in the male genital tract (testis, prostate, and epididymis) (Erdos and Skidgel, '87). Evidence is emerging that plasma ACE inhibition and hemodynamic responses are separable (Lees et al., '92). Prolonged treatment with an ACEI results in an increase of plasma ACE but a decrease of ACE in the renal cortex and renal brush border (Michel et al., '93). This indicates that plasma and epithelial ACE are subject to local regulatory factors. The renal proximal convoluted tubule contains angiotensinogen, ACE, and angioten$\sin$ II receptors (Moe et al., '93; Jackson et al., '91). Moe et al. ('93) found that renin could not be found in tubules from normal rats, but after enalapril administration, renin was found. This was interpreted as evidence of a tissue RAS that could generate angiotensin II to locally regulate sodium absorption.

It has been suggested that in part the effects of ACEIs are due to a locally acting, prostaglandin-dependent component to their hypotensive action. Linz et al, ('93) reported that when bradykinin degradation was inhibited by ramipril, formation of the endothelial autacoids, nitric oxide and prostacyclin, was enhanced, which they felt contributed to the beneficial effects of the drug. Similar conclusions were reached by others (Vanhoutte et al., '93; Busse et al., '93). On the other hand, Gerber et al. ('93) found that while indomethacin reduced the urinary excretion of prostacyclin metabolite by more than $50 \%$, it had no effect on the hypotensive effect of captopril or enalapril. They concluded that neither ACEI had a significant prostacyclin-dependent component to its hypotensive action, and Gansevoort et al. ('94) concluded that the antiproteinuric and renal hemodynamic effects of ACEIs were primarily due to interference in the RAS, rather than the bradykinin system. For now, the relation of the effects of the ACEIs to bradykinin degradation and prostaglandin production is not resolved. These two hormones may be acting at the tissue level without correlated change in blood or excretion levels. Involvement of the prostaglandin system in ACEI fetopathy seems possible, particularly given the number of reported instances of renal tubular dysgenesis (RTD)/fetal-neonatal anuria associated with nonsteroidal anti-inflammatory agent exposure (vide infra).

Tissue kinin generation and degradation are coordinately regulated during intrauterine development, while circulating angiotensin II and ACE activity change reciprocally (Yosipiv et al., '94). It appears that kinins and angiotensin II influence the development of ACE. It has been established that the RAS is active in fetal life, when it plays an essential role in maintaining GFR under conditions of low renal perfusion pressure (Jelinek et al., '86). At least in the lamb, it seems that the RAS is more active in the fetus than in the neonate (Binder and Anderson, '92).

Angiotensin II may also act on the growth of its target tissues. Some cells, such as those of the adrenal cortex, show induction of cell division by angiotensin II. The mechanism by which angiotensin II induces hyperplasia of its target tissues is largely unknown but may be from a direct action on proto-oncogene synthesis or an indirect action on growth factor secretion (Clauser et al., '92). As previously noted, the subtypes of angiotensin II receptors may function differentially as growth factors (Shanmugam et al., '94).

\section{ANIMAL STUDIES}

Classical studies of the ACEIs given during the period of organogenesis to rats and rabbits have failed to demonstrate an increased incidence of malformation. To emphasize a point made previously, lack of teratogenicity does not mean lack of fetotoxicity. The administration of ACEIs to commonly used laboratory animals, in late gestation and during lactation, in doses comparable to those used in human therapy, has been associated with significant fetal and neonatal wastage. These are fetotoxic not teratogenic effects. However, as described below, none of these species is an especially good model for the ACEI fetopathy seen in humans. So far, no exploration of maternal and fetal ACEI effects and physiology seems to have been done in nonhuman primates which might be much better models of the effects seen in humans; the development of such models should be encouraged.

\section{Rabbit model}

The adult rabbit is particularly sensitive to ACEIs, showing a greater antihypertensive effect than does the rat or dog. As measured by blockade of the acute pressor response to exogenous angiotensin 1, enalaprilat and captopril are of equal potency in pregnant and nonpregnant rabbits (Manson, personal communication). The administration of $2.5-5.0 \mathrm{mg} / \mathrm{kg} / \mathrm{day}$ of captopril to pregnant rabbits yielded pregnancy loss rates ranging from 37 to $92 \%$ (Broughton-Pipken et al., '80, ' 82 ; Ferris and Weir, ' 82 ). The ED50 values for blockade of the pressor response to angiotensin I by enalaprilat in the rabbit, rat, and dog were $2.8,5.1$, and 6.4 $\mathrm{mg} / \mathrm{kg}$, respectively. Comparable ED50 values for captopril in these 3 species were $2.88,26.1$, and $80 \mathrm{mg} / \mathrm{kg}$, respectively (Manson, personal communication). The basis for this sensitivity in rabbits is not known.

The late gestation rabbit fetus has been shown to be highly sensitive to the fetotoxic effects of ACEIs. When 
administered in the human therapeutic range, ACEIs produce fetal deaths in mid to late gestation, with a peak effect on GD 26 (Keith et al., '82; Broughton-Pipkin et al., '82; Minsker et al., '90). Maternal toxicity, as evidenced by elevation of blood urea nitrogen (BUN) and creatinine, and occasionally maternal death, occurs at the same treatment levels as those causing fetal deaths. Fetal deaths observed in rabbits with ACEI treatment may be the result of decreased placental perfusion commensurate with systemic hypotension in the mother, rather than of a direct effect on fetal renal perfusion (Ferris and Weir, '82; Binder et al., '89; Binder and Faber, '92). Captopril studies in the rabbit showed no effect on amniotic fluid volume, amniotic fluid electrolyte composition, or fetal plasma urea nitrogen, creatinine, or calcium levels (Manson, personal communication). When plasma volume was expanded by saline supplementation, maternal toxicity was reduced but fetal deaths continued, particularly at higher dosage levels (enalapril $30 \mathrm{mg} / \mathrm{kg} /$ day) (Minsker et al., '90).

\section{Rat model}

The maturation of the RAS in the fetal and neonatal rat kidney has been thoroughly studied (Ice et al., '88). Expression of the gene for the angiotensin II receptor was not detected in the liver of newborn rats, but in their kidneys gene expression was 2.5 times higher than in the adult (Iwai et al., '91). Decreasing concentrations of plasma renin from fetal, to newborn, to neonatal rats are consistent with increased activity of the RAS in immature animals (Jelinek et al., '86). Renin was first detected by immunostaining in the kidney on GD 19, when it was located in the arcuate and interlobular arteries. On GD 20, renin also appeared in the afferent arteriole. With advancing age, detectable renin disappeared progressively from the arcuate and interlobular arteries until it was restricted primarily to the afferent arteriole in the 20-day-old postnatal pup and finally only to the juxtaglomerular apparatus in the adult kidney. A similar but more rapid progression of maturation has been observed in the mouse (reviewed by Ice et al., '88). Studies of the synthesis of renin mRNA in the rat have shown the same pattern and timing (Gomez et al., '89).

The relevance of these findings to reproductive and developmental toxicity studies of ACEIs in rats is that the RAS develops late in gestation, beyond the time when treatment typically is administered in a segment II rat developmental toxicity study (GD 6-17). Not surprisingly, then, results from these studies have uniformly failed to reveal any adverse effects on fetuses, with the exception of decrease in fetal body weight and ossification at treatment levels that also produce evidence of maternal body weight decreases.

Interestingly, results from female fertility and late gestation/lactation studies, in which ACEI exposure occurred during the critical period of fetal renin synthe- sis (GD 19), have demonstrated adverse effects on neonates (Robertson et al., '86). At high treatment levels (approximately $30-300 \mathrm{mg} / \mathrm{kg} / \mathrm{day}$ for enalapril and lisinopril), pup deaths occurred during lactation. At lower treatment levels $(10 \mathrm{mg} / \mathrm{kg} / \mathrm{day})$, decreased preand postweaning body weight gain was observed. Similar findings have been obtained with other ACEIs, quinapril (Dostal et al., '91) and rentiapril (Cozens et al., '87).

Late gestation/lactation studies, with treatment from GD 15 to the end of lactation, would seem to provide the most sensitive appraisal of ACEI effects on rat pups. Kidneys from weanlings whose mothers received quinapril during late gestation (GD 15 on) and/or lactation had juxtaglomerular cell hypertrophy (Dostal et al., '91; Graziano et al., '93), although the latter authors reported they observed no morphological changes in the renal tubules and no adverse effects on renal function. Early postnatal treatment with the ACEIs enalapril and captopril, and the angiotensin receptor-1 blocker losartan, but not the angiotensin receptor-2 blocker PD-123319, in the spontaneously hypertensive rat (SHR) and the normotensive strains WKY and WR produced persistent, irreversible histopathological renal changes in adult life, long after the treatment had stopped. These abnormalities were associated with impaired urine concentrating ability (Friberg et al., '94). This should be looked at for other ACEIs. For the most part, histopathology from such kidneys has either not been done or not been reported in the literature.

All in all, it does not appear that the rat is a suitable model for predicting or understanding ACEI fetopathy in humans. The RAS develops much later in gestation in rats than in humans, and in rats toxicity is manifested in neonates and weanlings, while in humans the major manifestations are seen prenatally and at birth. Also, from the available data, it appears that the rat placenta is an effective barrier to ACEI penetration into the fetal compartment, although more data are needed on this point.

\section{Sheep model}

The chronically catheterized sheep serves as an excellent model to study the cardiovascular and renal changes in the maternal and fetal compartments occurring during pregnancy (Magness et al., ' 85 ; Hill and Lumbers, ' 88 ). When captopril, which crosses the sheep placenta and blocks the fetal RAS, was administered in late pregnancy $($ GD $119-133$, term $=147$ ) at $2.8-3.5$ $\mathrm{mg} / \mathrm{kg}$ IV to the ewe following exogenously administered angiotensin I, maternal blood pressure was transiently reduced and returned to normal within $2 \mathrm{hr}$. Fetal blood pressure remained reduced for up to 2 days, and 7 of 8 lambs were stillborn (Broughton-Pipkin et al., '82).

In a similar model, fetal renal function was studied in sheep given captopril (GD 123-133) at an infusion rate of $15 \mathrm{mg}$ IV for 4 days, followed by an intrafetal 
infusion of angiotensin II ( $6 \mu \mathrm{g} / \mathrm{kg} / \mathrm{hr})$. Fetal GFR decreased from an initial 4.2 to $2.7 \mathrm{ml} / \mathrm{min}$ after maternal captopril administration, and 3 days later it was 1.5 $\mathrm{ml} / \mathrm{min}$. When the fetuses were given angiotensin II intravenously, fetal GFR returned to a mean of 3.4 $\mathrm{ml} / \mathrm{min}$. It was concluded that a small fall in fetal arterial pressure partly contributed to the fall in fetal GFR but efferent arteriolar tone fell also so that the filtration pressure fell further. Thus maintenance of fetal renal function depends on the integrity of the fetal RAS (Lumbers et al., '92, '93).

Enalapril has also been studied in the sheep model (Broughton-Pipkin and Wallace, '86). Enalapril was given at a dose of 1 or $2 \mathrm{mg} / \mathrm{kg}$ IV at a median gestational age of 128 days. A pressor response to exogenous angiotensin I (5 $\mu \mathrm{g}$ IV) was first established in the maternal compartment: maternally administered angiotensin I had no effect on fetal blood pressure. Following the administration of enalapril, maternal blood pressure was decreased for $30 \mathrm{~min}$, but there was no effect on fetal heart rate, plasma renin, or ACE activity. At the high dose of enalapril tested, there was a transient fall in fetal blood pressure, considered to be due to changes in uteroplacental blood flow rather than to a direct effect of the drug on the fetus. Trace amounts of enalapril were found in fetal plasma, and levels of its active metabolite, enalaprilat, were undetectable in three of four fetuses. One unexplained fetal death occurred in the $2 \mathrm{mg} / \mathrm{kg}$ enalapril group. It was concluded that there was minimal transfer of the drug into the fetal compartment. Thus, the sheep model may not be specifically informative about the effects of exposure on the human fetus for all ACEIs, for enalapril does cross the human placenta and evidently acts directly on the fetus.

\section{FEATURES OF ACEI FETOPATHY RTD}

RTD is characterized by dilation of Bowman's spaces and tubules, diminished to absent differentiation of proximal convoluted tubules, and increased cortical and medullary mesenchyme (and later fibrosis) (Fig. 2). The histological changes in the kidney strongly suggest ischemic injury, with the added component of deficient tubular differentiation most easily confirmed by failure of periodic acid Schiff stain to stain the brush border of proximal convoluted tubules. It has been my experience that, unless specifically looked for, the histopathological changes of RTD in the fetal/neonatal kidney can be and have been missed. RTD was fully described in four cases of ACEI fetopathy (Cunniff et al., '90; Pryde et al., '93) and has been observed in a number of unreported cases.

To examine the specificity of this set of histopathological findings for ACEI exposure, Martin et al. ('92) examined the kidneys of nine fetuses whose mothers were chronically hypertensive. Three of these mothers used antihypertensive agents throughout pregnancy, including one who used an ACEI. The tubular morphology of these kidneys was compared with the renal tubules of 20 normal controls, 13 fetuses with various multiple malformation syndromes, and 6 cases of the twin-twin transfusion syndrome. Features of RTD were identified in two cases of twin-twin transfusion syndrome, the ACEI-exposed case, and one methyldopaexposed case. In trying to tie these findings and evidence from the literature together it was hypothesized that the primary mechanism by which ACEIs affect development of the fetal kidney is through decreased renal blood flow (Martin et al., '92). This hypothesis was supported by Landing et al. (94), who noted that RTD has been seen as a unilateral lesion in young infants with renal artery stenosis due to arteritis or medial arterial calcinosis and resembles the renal tubular atrophy of end-stage kidney diseases such as glomerulonephritis, tubulointerstitial kidney disease, obstructive uropathy and pyelonephritis, graft rejection of transplanted kidneys, and the renal parenchymal changes associated with protracted dialysis therapy. Landing et al. ('94) reported that labeled lectins that differentially mark proximal convoluted, distal convoluted, connecting, and collecting tubules in RTD showed no distinctive differences in the staining patterns of their hypoplastic renal tubules compared with those associated with postnatal renal artery obstruction or various types of end-stage renal disease. These findings suggest that the renal tubular changes seen in some if not all the conditions cited, including RTD, are the result of renal ischemia.

RTD, with hypoplasia especially of renal proximal convoluted tubules and clinical neonatal anuria or oliguria, has also been reported as a congenital familial (autosomal recessive) disease, variably with features of oligohydramniotic deformation and pulmonary hypoplasia (reviewed by Allanson et al., '92). According to Landing et al. ('94), the microscopic appearance of the kidneys in hereditary RTD is indistinguishable from that seen in cases of renal ischemia. It must also be noted that RTD has been reported in association with exposure to nonsteroidal anti-inflammatory agents, particularly indomethacin (Simeoni et al., '89; Restaino et al., '91; Bavoux, '92; Buderus et al., '93; Voyer et al., '94). Thus it would seem that RTD is not specific for ACEI exposure, but rather that ACEIs are rather proficient at creating the conditions that lead to RTD.

\section{Hypocalvaria}

Apart from the renal failure and related abnormalities discussed above, six ACEI-exposed cases have had hypoplasia of the membranous bones of the skull, or hypocalvaria (Duminy and Burger, '81; Rothberg and Lorenz, '84; Mehta and Moda, '89; Pryde et al., '93). In this condition, the calvarial bones are found to be normal in position and shape, but greatly reduced in size 

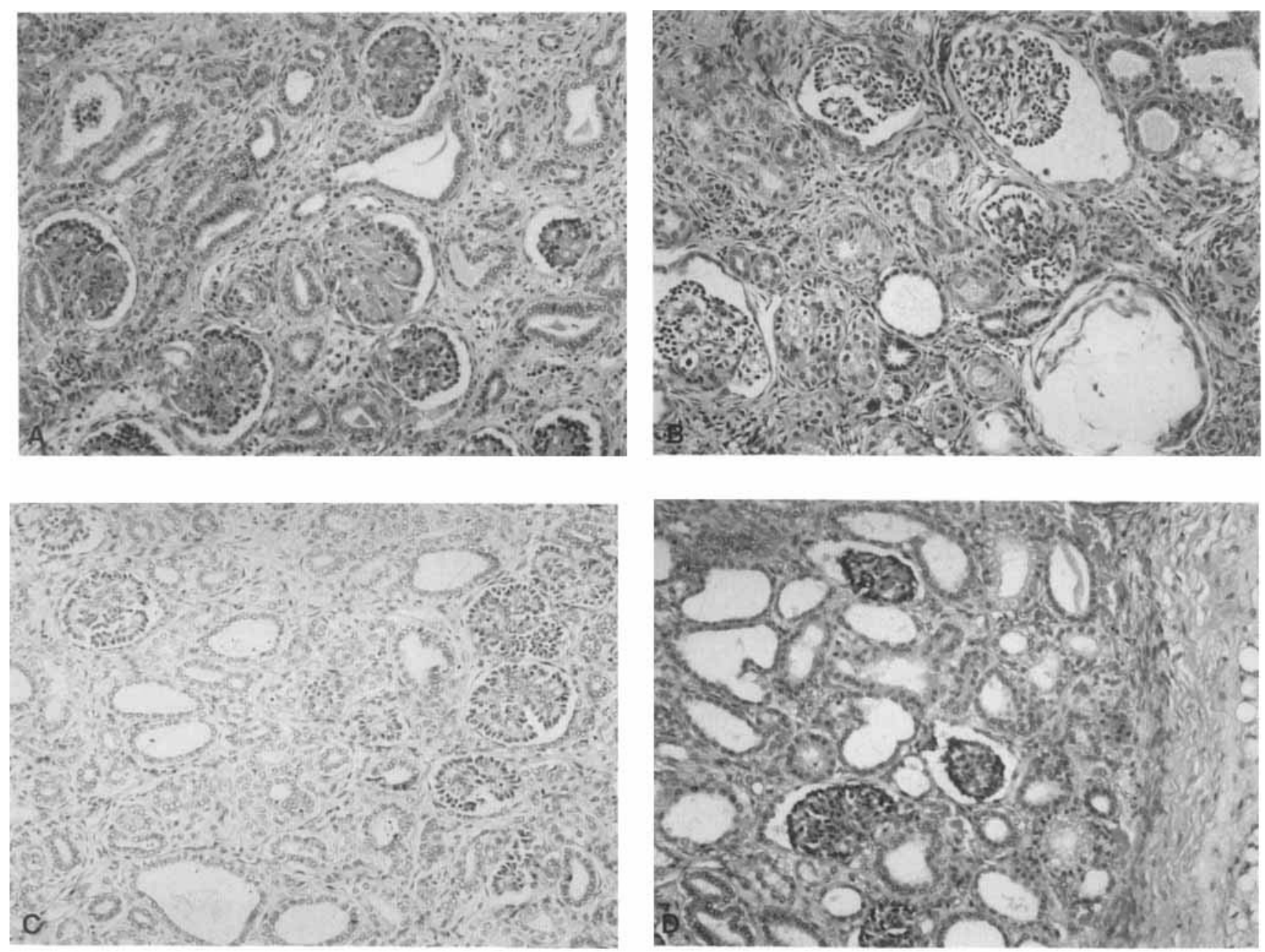

Fig. 2. RTD in four different cases of ACEI fetopathy; note particularly the ductular ectasia, dilation of Bowman's spaces, and poor to no differentiation of proximal convoluted tubules. $\times 20$.

(Fig. 3). The sutures and fontanels are symmetrically enlarged, and in severe cases, the normally developing brain is essentially unprotected by skull and liable to trauma during labor and delivery. Although there are now only a total of six cases in which this skull lesion is specifically described, I believe it is more common but unrecognized; it seems that many cases may be classified as enlarged fontanels with widely split sutures, but in instances in which hydrocephaly or macroencephaly are not present. Lacking age-specific morphometrics for the size of the calvarial bones, the distinction of hypocalvaria in milder cases is admittedly a subjective assessment.

The cause of the hypoplastic calvaria found with ACEI exposure is unknown. Endochondral bone and membranous bone grow and develop in entirely different ways. Long bones develop in a low oxygen environment since nutrition takes place by diffusion through the cartilaginous epiphyses. Membranous bones, on the other hand, have a high degree of vascularity, and a high oxygen tension is required for their growth. The presumed fetal hypotension produced by ACEI exposure may result in hypoxic effects and thus a hypoplastic calvaria (Barr and Cohen, '91). A more remote possibility is that inhibition of angiotensin II may concomitantly inhibit one of the variety of growth factors involved in calvarial bone development.

\section{Intrauterine growth restriction}

The status of the fetal RAS in pregnancies complicated by severe intrauterine growth restriction, and its possible relationship to elevated fetoplacental vascular resistance, was explored by Kingdom et al. ('93). In an intrauterine growth restriction group, cord venous angiotensin II was markedly elevated compared with controls, but angiotensin receptor concentration was not significantly altered, and no changes in angiotensin receptor affinity were observed. This suggests that there is augmentation of the fetal RAS in at least some forms of intrauterine growth restriction and that re- 


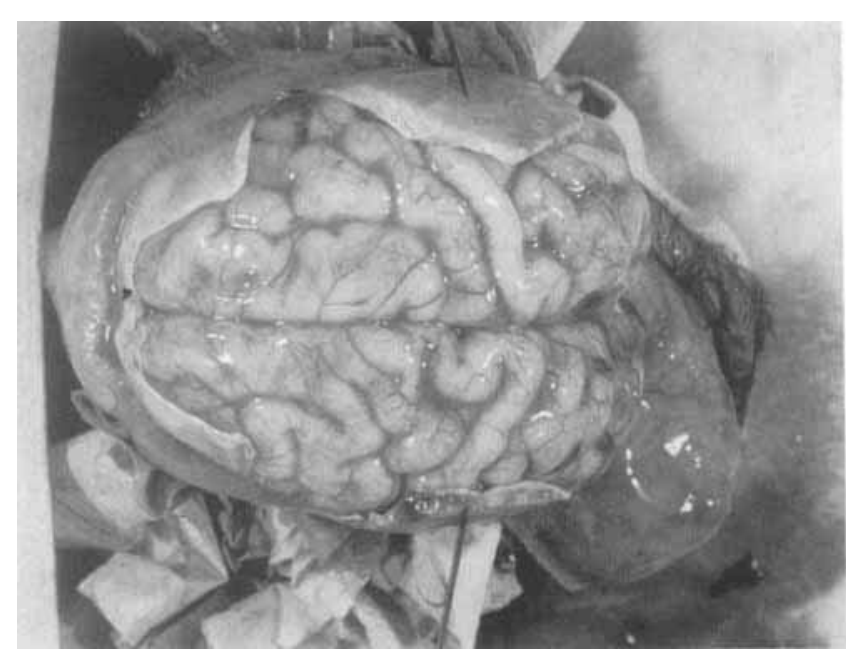

Fig. 3. Hypocalvaria. In this severe example, the fibrous tissue comprising the fontanels and sutures has been removed, leaving only the calvarial bone, to demonstrate the diminutive size of the bones. (Reproduced from Barr and Cohen, '91, with permission of WileyLiss.)

sponsiveness of the fetoplacental vasculature to angiotensin II is not diminished as might be expected from the elevated plasma angiotensin II levels. Angiotensin II may contribute to the increased fetoplacental vascular resistance observed in this disorder.

Intrauterine growth restriction (birth weight centile $<10 \%$ ) has been observed in 21 of 27 cases of ACEI fetopathy for which birth weight information was given (Pryde et al., '93). In a single case (Pryde et al., '93: \#1), limb lengths were disproportionately short by measurement, although not to the degree that a diagnosis of short-limbed dwarfism would be made. No data on limb lengths are given for other cases. From measurement of limb lengths in other fetuses with presumed hypotension, it is hypothesized that relative growth lag of the limbs is a marker of an adaptive shift of circulatory pattern in the compromised fetus, with circulation diminished to the periphery to preserve central perfusion (unpublished observations). Thus it could be predicted that a feature of ACEI fetopathy would be some shortening of the limbs.

\section{PDA}

A final observation which appears in reviewing reports of neonatal outcomes in pregnancies exposed to the ACEIs is the persistence of a PDA. While this may be associated with the high frequency of prematurity in the cases reported, it is suggested that there appears also to be an increased need for surgical intervention. Out of seven PDA cases reported in association with ACEI exposure, three required surgical ligation (Boutroy et al., '84; Caraman et al., '84; Plouin and Tchobroutsky, '85; Kreft-Jais et al., '88). Given the possible effect of the ACEIs on the fetal bradykinin-pros- taglandin system, which would be expected to increase prostaglandin $E$ and prostacyclin systemically and perhaps locally, the possibility that prenatal ACEIs may inhibit ductal closure needs to be considered. Certainly, more data are needed before any firm conclusion can be reached on this subject.

\section{COULD IT BE THE MATERNAL DISEASE ITSELF AND NOT THE DRUG?}

ACEI fetopathy infants have been born to mothers whose hypertension was of widely varying etiology, including lupus erythematosus, renovascular hypertension, nephrotic syndrome, glomerulonephritis, renal transplantation, preeclampsia, and essential hypertension (Pryde et al., '93). Oligohydramnios, intrauterine growth restriction, and fetal distress are not uncommon complications of hypertensive pregnancies. However, as discussed above, there is evidence that indicates the oligohydramnios, hypotension, and anuria of ACEI fetopathy are truly drug-related rather than simply phenomena of the underlying maternal disease process. The evolution of oligohydramnios followed by the delivery of a neonate with prolonged hypotension and anuria has not been included in the well-described list of complications of maternal hypertension and its traditional therapy, although one case of RTD has been observed under these circumstances (Martin et al., '92). With ACEI exposure, the probability is high that the oligohydramnios is in fact due to a drug-related fetal hypotension and renal failure that persists into the neonatal period. Evidence in support of this hypothesis is the occurrence of profound hypotension and anuria in some neonates given low doses of ACEIs for treatment of hypertension (Tack and Perlman, '88; Perlman and Volpe, '89; Scott and Purohit, '89; Wells et al., '90). Further, when ACE activity was measured in ACEIexposed hypotensive neonates it was found to be profoundly blunted and appeared to normalize only after dialysis removed the otherwise renally excreted drug (Schubiger et al.,' '88; Pryde et al., '93). There are reports that the onset of oligohydramnios was temporally related to the initiation of ACEI therapy (Guignard et al., '81; Schubiger et al., ' 88 ), and in one case the amniotic fluid volume increased toward normal after the ACEI was discontinued (Broughton-Pipkin et al., '89).

\section{SUMMARY}

Occasionally there is a drug whose record in pregnancy is so frequently associated with adverse outcome of so specific a pattern that it becomes clear that its use must be restricted before scientific proof from epidemiological studies is obtained. I believe this to be the case with the drug class of ACEIs. There are mammalian models suggesting substantial fetotoxicity in a doserelated fashion. There is a strong and consistent pattern to the reported cases of ACEI-related adverse outcomes: the syndrome of oligohydramnios-anuria, 
neonatal hypotension, renal dysplasia, and hypocalvaria is too specific in association with the use of these drugs to be ignored. There is a very plausible biologic mechanism to explain the relationship. The features of ACEI fetopathy suggest that the underlying pathogenetic mechanism is fetal hypotension, which may also result from other exposures. Thus, while the fetopathy may not be truly specific to ACEIs, they are particularly liable to produce adverse fetal renal effects with their sequels (anuria-oligohydramnios, pulmonary hypoplasia, growth restriction) and hypocalvaria.

\section{RECOMMENDATIONS}

It is advised that ACEIs not be prescribed to pregnant women. Based on current information, exposure to ACEIs in the first trimester should not be considered an indication for terminating a pregnancy. In such cases, an alternative antihypertensive regimen should be substituted for the drug prior to entering the second trimester. If a woman is inadvertently on ACEI therapy in the second or third trimesters of pregnancy, she should be monitored for signs of fetal toxicity, including oligohydramnios, growth restriction, or fetal distress. Although oligohydramnios has been observed to reverse when the ACEI is discontinued, a cautionary note must be sounded. The signs of fetal toxicity may not be detected until after irreversible damage to the fetus has occurred.

In the case of an ACEI-exposed fetus, at the time of delivery or before, the pediatricians should be notified of the potential for neonatal hypotension and anuria and the possible need to attempt early dialysis to remove the otherwise renally excreted drug. However, the combination of hypotension and anuria makes both peritoneal and hemodialysis extremely difficult, and the mortality rate is exceptionally high. Because the damage that can occur from these drugs is so severe, it is urged that their prescription to women of childbearing potential be limited and, if they must be used, that the women be warned about risks to the fetus and be monitored very closely for the occurrence of pregnancy.

\section{ACKNOWLEDGMENTS}

Two highly esteemed colleagues, Dr. Jeanne Manson and Dr. Aileen Sedman, contributed helpful information, perceptive comments, and intelligent discussion during the preparation of this review. For her role in getting the product labeling of the ACEIs changed to warn of the fetal risks, Dr. Sedman warrants special thanks. Thanks are also due to the journal reviewers for their cogent suggestions.

\section{LITERATURE CITED}

Al-Harbi, M.M., O.A. Al-Shabanah, N.M.A. Al-Gharably, and M.W. Islam (1992) The effect of maternal administration of enalapril on fetal development in the rat. Res. Commun. Chem. Pathol. Pharmacol., 77:347-385.

Allanson, J.E., A.G.W. Hunter, G.S. Mettler, and C. Jimenez (1992)
Renal tubular dysgenesis-A not uncommon autosomal recessive syndrome: A review. Am. J. Med. Genet., 43:811-814.

Al-Shabanah, O.A., M.M. Al-Harbi, N.M.A. Al-Gharably, and M.W. Islam (1991) The effect of maternal administration of captopril on fetal development in rat. Res. Commun. Chem. Pathol. Pharmacol., 73:221-230.

Bakhle, Y.S. (1968) Conversion of angiotensin I to angiotensin II by cell-free extracts of dog lung. Nature, 220:919-921.

Bakris, G.L. (1993) Angiotensin-converting enzyme inhibitors and progression of diabetic nephropathy. Ann. Int. Med., 118:643-644.

Barr, M., and M.M. Cohen (1991) ACE inhibitor fetopathy and hypocalvaria: The kidney-skull connection. Teratology, 41:485-495.

Bavoux, F. (1992) Toxicite foetal des anti-inflammatoires non steroidiens. Presse Med., 21:1909-1912.

Binder, N.D., and D.F. Anderson (1992) Plasma renin activity responses to graded decreases in renal perfusion pressure in fetal and newborn lambs. Am. J. Physiol., 262:R524-R529.

Binder, N.D., and J.J. Faber (1992) Effects of captopril on blood pressure, placental blood flow and uterine oxygen consumption in pregnant rabbits. J. Pharmacol. Exp. Ther., 260:294-299.

Binder, N., J. Faber, and D. Anderson (1989) The effect of captopril on blood pressure, uterine blood flow and oxygen consumption in the pregnant rabbit. Clin. Res., 37:6A.

Blythe, W.B. (1983) Captopril and renal autoregulation. N. Engl. J. Med., 308:390-391.

Boutroy, M.J., P. Vent, B. Hunault de Ligny, and A. Milton (1984) Captopril administration in pregnancy impairs fetal angiotensin converting enzyme activity and neonatal adaptation. Lancet, $2: 935-936$.

Brent, R.L, and D.A. Beckman (1991) Angiotensin-converting enzyme inhibitors, an embryopathic class of drugs with unique properties: Information for clinical teratology counselors. Teratology, 43:543546.

Broughton-Pipkin, F., and C.P. Wallace (1986) The effect of enalapril (MK-421), an angiotensin-converting enzyme inhibitor, on the conscious pregnant ewe and her foetus. Br. J. Pharmacol., 87:533-542.

Broughton-Pipkin, F., S.R. Turner, and E.M. Symonds (1980) Possible risk with captopril during pregnancy: Some animal data. Lancet, $2: 1256$.

Broughton-Pipkin, F., E.M. Symonds, and S.R. Turner (1982) The effect of captopril (SQ 14,225) upon mother and fetus in the chronically cannulated ewe and in the pregnant rabbit. J. Physiol., 323: 415-422.

Broughton-Pipkin, F., P.N. Baker, and E.M. Symonds (1989) Angiotensin-converting enzyme inhibitors in pregnancy. Lancet, 2:96-97.

Buderus, S., B. Thomas, H. Fahnenstich, and S. Kowalewski (1993) Renal failure in two preterm infants: Toxic effect of prenatal maternal indomethacin treatment. Br. J. Obstet. Gynaecol., 100:9798

Busse, R., I. Fleming, and M. Hecker (1993) Endothelium-derived bradykinin: Implications for angiotensin-converting enzyme inhibitor therapy. J. Cardiovasc. Pharmacol, 22(Suppl. 5):S31-S36.

Caraman, P.L., A. Miton, B. Hurault de Ligny, et al. (1984) Grossesses sous captopril. Therapie, 39:59-62.

Clauser, E., C. Bihoreau, C. Monnot, et al. (1992) Angiotensin-II, a growth factor. Diabete Metabol., 18:129-136.

Cooke, H.M., and A. Debesse (1994) Angiotensin-converting enzyme inhibitor-induced renal dysfunction: Recommendations for prevention. Int. J. Clin. Pharmacol. Ther., 32:65-70.

Cozens, D.D., S.J. Barton, R. Clark, E.W. Hughes, J.M. Offer, and Y. Yamamoto (1987) Reproductive toxicity studies of rentiapril. Arz. Forsch./Drug Res., 37:164-169.

Cunniff, C., K.L. Jones, K. Phillipson, S. Short, and J. Wujek (1990) Oligohydramnios and renal tubular malformation associated with maternal enalapril use. Am. J. Obstet. Gynecol., 162:187-189.

Cushman, D.W., and M.A. Ondetti (1991) History of the design of captopril and related inhibitors of angiotensin-converting enzyme. Hypertension, 17:589-592.

Devoy, M.A.B., C.R.V. Tomson, M.E. Edmunds, J. Feehally, and J. 
Walls (1992) Deterioration in renal function associated with angiotensin-converting enzyme inhibitor therapy is not always reversible. J. Int. Med., 232:493-498.

Dostal, L.A., S.N. Kim, J.L. Schardein, and J.A. Anderson (1991) Fertility and perinatal/postnatal studies in rats with the angiotensin-converting enzyme inhibitor, quinapril. Fund. Appl. Toxicol., 17:684-695.

Ducret, F., P.H. Pointet, B. Laurengeon, C. Jacoulet, and J. Gagnaire (1985) Grossesse sous inhibiteur de l'enzyme de conversion. Presse Med., 14:897.

Duminy, P.C., and P. du T. Burger (1981) Fetal abnormality associated with the use of captopril during pregnancy. S. Afr. Med. J., $60: 805$.

Ehlers, M.W., and J.F. Riordan (1989) Angiotensin-converting enzyme: New concepts concerning its biological role. Biochemistry, 28:5311-5316.

Endo, M., Y. Yamada, M. Kohno, T. Suzuki, M. Otsuka, and O. Takaiti (1992) Metabolic fate of the new angiotensin-converting enzyme inhibitor imidapril in animals. IV. Placental transfer and secretion into milk in rats. Arz. Forsch./Drug Res., 42:483-489.

Erdos, E.G., and R.A. Skidgel (1987) The angiotensin I-converting enzyme. Lab. Invest., 56:345-348.

Ferreira, S.H. (1965) A bradykinin-potentiating factor (BPF) present in the venom of Bothrops jararaca. Br. J. Pharmacol., 24:163-169.

Ferris, T.F., and E.K. Weir (1982) Effect of captopril on uterine blood flow and prostaglandin $\mathrm{E}$ synthesis in the pregnant rabbit. J. Clin. Invest., 71:809-815.

Fiocchi, R., P. Ligney, R. Fagard, J. Staessen, and A. Amery (1984) Captopril during pregnancy. Lancet, 2:1153.

Friberg, P., B. Sundelin, S.O. Bohman, et al. (1994) Renin-angiotensin system in neonatal rats: Induction of a renal abnormality in response to ACE inhibition or angiotensin-II antagonism. Kidney Int., 45:485-492.

Fujii, T., and T. Nakatsuka (1985) Enalapril (MK-421) oral teratogenicity in the rat. Yakuri To Chiryo, 13:529-548.

Fujii, T., T. Nakatsuka, S. Hanada, T. Komatsu, and H. Okiyama (1985) Enalapril (MK-421) oral teratogenicity study in the rat. Yakuri To Chiryo, 13:519-528.

Gansevoort, R.T., D. Dezeeuw, and P.E. Dcjong (1994) The antiproteinuric effect of ACE inhibition mediated by interference in the renin-angiotensin system. Kidney Int., 45:861-867.

Garay, R., N. Senn, and J.P. Ollivier (1994) Erythrocyte ion transport as indicator of sensitivity to antihypertensive drugs. Am. J. Med. Sci., 307(Suppl. 1):S120-S125.

Gavras, H. (1988) The place of angiotensin-converting enzyme inhibitors in the treatment of cardiovascular diseases. N. Engl. J. Med., 319:1541-1543.

Gerber, J.G., G. Franca, R.L. Byyny, M. Loverde, and A.S. Nies (1993) The hypotensive action of captopril and enalapril is not prostacyclin dependent. Clin. Pharmacol. Ther., 54:523-532.

Gomez, H.J., V.J. Cirillo, and F. Moncloa (1987) The clinical pharmacology of lisinopril. J. Cardiovasc. Pharmacol., 9(Suppl. 3):S27S34.

Gomez, R., K. Lunch, B. Sturgill, J. Elwood, R. Chevalier, R. Carey, and M. Peach (1989) Distribution of renin mRNA and its protein in the developing kidney. Am. J. Physiol., 257:F850-F858.

Graves, S.W., T.J. Moore, and E.W. Seely (1992) Increased platelet angiotensin-II receptor number in pregnancy-induced hypertension. Hypertension, 20:627-632.

Graziano, M.J., L.A. Dethloff, H.E. Griffin, and D.G. Pegg (1993) Effects of the angiotensin-converting enzyme inhibitor quinapril on renal function in rats. Arch. Int. Pharmacodyn. Ther., 324:87-104.

Grone, H.J., M. Simon, and E. Fuchs (1992) Autoradiographic characterization of angiotensin receptor subtypes in fetal and adult human kidney. Am. J. Physiol., 262:F326-F331.

Guignard, J.P. (1982) Renal function in the newborn infant. Pediatr. Clin. North Am., 29:777-790.

Guignard, J.P., F. Burgener, and A. Calaine (1981) Persistent anuria in a neonate: A side effect of captopril? Int. J. Pediatr. Nephrol., $2: 133$.
Guthrie, R. (1993) Fosinopril: An overview Am. J. Cardiol., 72:H22H24.

Hall, J.E., A.C. Guyton, T.E. Jackson, T.G. Coleman, T.E. Lohmeier, and N.C. Trippodo (1977) Control of glomerular filtration rate by renin-angiotensin system. Am. J. Physiol., 233:F366-F372.

Hanssens, M., M.J.N.C. Keirse, F. Vankelecom, and F.A. Van Assch (1991) Fetal and neonatal effects of treatment with angiotensinconverting enzyme inhibitors in pregnancy. Obstet. Gynecol., 78: $128-135$.

Hill, K., and E. Lumbers (1988) Renal function in adult and fetal sheep. J. Dev. Physiol, 10:149-159.

Hricik, D.E., P.J. Browing, R. Kopelman, W.E. Goorno, N.E. Madias, and V.J. Dzau (1983) Captopril induced functional renal insufficiency in patients with bilateral renal artery stenosis or renal artery stenosis in a solitary kidney. N. Engl. J. Med., 308:373-376.

Ice, K.S., K.M. Geary, R.A. Gomez, D.W. Johns, M.J. Peach, and R.M. Carey (1988) Cell and molecular studies of renin secretion. Clin. Exp. Hypertens. Theor. Pract., A10:1169-1187.

Iwai, N., Y. Yamano, S. Chaki, et al. (1991) Rat angiotensin II receptor: cDNA sequence and regulation of the gene expression. Biochem. Biophys. Res. Commun., 177:299-304.

Jackson, B., F.A.O. Mendelsohn, and C.I. Johnston (1991) Angiotensin-converting enzyme inhibition: Prospects for the future. J. Cardiovasc. Pharmacol., 18:S4-S8.

Jelinek, J., R. Hackenthal, U. Hilgenfeldt, G. Schaechtelin, and E. Hackenthal (1986) The renin-angiotensin system in the perinatal period in rats. J. Dev. Physiol., 8:33-41.

Johnston, C.I., L.M. Burrell, R. Perich, K. Jandeleit, and B. Jackson (1992) The tissue renin-angiotensin system and its functional role. Clin. Exp. Pharmacol. Physiol., Suppl. 19:1-5.

Johnston, C.I., B. Fabris, and K. Yoshida (1993) The cardiac reninangiotensin system in heart failure. Am. Heart J., 126:756-760.

Keith, I.M., J.A. Will, and E.K. Weir (1982) Captopril: Association with fetal death and pulmonary vascular changes in the rabbit. Proc. Soc. Exp. Biol. Med., 170:378-383.

Kingdom, J.C.P., J. McQueen, J.M.C. Connell, and M.J. Whittle (1993) Fetal angiotensin-II levels and vascular (type-I) angiotensin receptors in pregnancies complicated by intrauterine growth retardation. Br. J. Obstet. Gynaecol., 100:476-482.

Knott, P.D., S.S. Thorp, and C.A.R. Lamont (1989) Congenital renal dysgenesis possibly due to captopril. Lancet, 1:451.

Kon, V., A. Fogo, I. Ichikawa, S.E. Hellings, and T. Bills (1993) Bradykinin causes selective efferent arteriolar dilation during angiotensin-I converting enzyme inhibition. Kidney Int., 44:545-550.

Kreft-Jais, C., C. Plouin, C. Tchobroutsky, and M.J. Boutroy (1988) Angiotensin-converting enzyme inhibitors during pregnancy: A survey of 22 patients given captopril and nine given enalapril. $\mathrm{Br}$. J. Obstet. Gynaecol., 95:420-422.

Landing, B.H., S.M. Ang, N. Herta, E.F. Larson, and M. Turner (1994) Labeled lectin studies of renal tubular dysgenesis and renal tubular atrophy of postnatal renal ischemia and end-stage kidney disease. Pediatr. Pathol., 14:87-99.

Lee, E.J.D. (1994) Population genetics of the angiotensin-converting enzyme in Chinese. Br. J. Clin. Pharmacol., 37:212-214.

Lees, K.R., I.B. Squire, and J.L. Reid (1992) The clinical pharmacology of ACE inhibitors: Evidence for clinically relevant differences. Clin. Exp. Pharmacol. Physiol., Suppl. 19:49-53.

Li, J., H.Y. Hu, and Y.N. Zhao (1992) Serum angiotensin-converting enzyme activity in pregnancy-induced hypertension. Gynecol. Obstet. Invest., 33:138-141.

Lindheimer, M.D., and A.I. Katz (1985) Hypertension in pregnancy (current concepts). N. Engl. J. Med., 313:675-680.

Linz, W., G. Wiemer, and B.A. Scholkens (1993) Contribution of bradykinin to the cardiovascular effects of ramipril. J. Cardiovasc. Pharmacol., 22(Suppl. 9):S1-S8.

Lumbers, E.R., N.M. Kingsford, R.I. Menzies, and A.D. Stevens (1992) Acute effects of captopril, an angiotensin-converting enzyme inhibitor, on the pregnant ewe and fetus. Am. J. Physiol., 262:R754R760.

Lumbers, E.R., J.H. Burrell, R.I. Menzies, and A.D. Stevens (1993) 
The effects of a converting enzyme inhibitor (captopril) and angiotensin-II on fetal renal function. Br. J. Pharmacol., 110:821-827.

Magness, R., K. Osei-Boaten, M. Mitchell, and C. Rosenfeld (1985) In vitro prostacyclin production by ovine uterine and systemic arteries: Effects of angiotensin II. J. Clin. Invest., 76:2206-2212.

Marre, M., P. Bernadet, Y. Gallois, et al. (1994) Relationships between angiotensin $I$ converting enzyme gene polymorphism, plasma levels, and diabetic retinal and renal complications. Diabetes, 43 : $384-388$.

Martin, R.A., K.L. Jones, A. Mendoza, M. Barr, and K. Benirschke (1992) Effect of ACE inhibition on the fetal kidney: Decreased renal blood flow. Teratology, 46:317-321.

Materson, B.J., and R.A. Preston (1994) Angiotensin-converting enzyme inhibitors in hypertension. Arch. Int. Med., 154:513-523.

Mehta, N., and N. Modi (1989) ACE inhibitors in pregnancy. Lancet, $2: 96$.

Michel, B., D. Stephan, M. Grima, M. Barthelmebs, and J.L. Imbs (1993) Effects of one-hour and one-week treatment with ramipril on plasma and renal brush border angiotensin-converting enzyme in the rat. Eur. J. Pharmacol., 242:297-243.

Minsker, D.H., W.J. Bagdon, J.S. MacDonald, R.T. Robertson, and D.L. Bokelman (1990) Maternotoxicity and fetotoxicity of an angiotensin-converting enzyme inhibitor, enalapril, in rabbits. Fund. Appl. Toxicol., 14:461-470.

Moe, O.W., K. Ujiie, R.A. Star, et al. (1993) Renin expression in renal proximal tubule. J. Clin. Invest., 91:774-779.

Perlman, J.M., and J.J. Volpe (1989) Neurologic complications of captopril treatment of neonatal hypertension. Pediatrics, 83:47-52.

Pinkney, J.H., and J.S. Yudkin (1994) Antihypertensive drugs: Issues beyond blood pressure control. Prog. Cardiovasc. Dis., 36:397-415.

Piper, J.M., W.A. Ray, and F.W. Rosa (1992) Pregnancy outcome following exposure to angiotensin-converting enzyme inhibitors. Obstet. Gynecol., 80:429-432.

Plouin, P.F., and C. Tchobroutsky (1985) Inhibition de l'enzyme de conversion de l'angiotensine au cours de la grossesse humaine: Quinze cas. Presse Med., 14:2175-2178.

Pryde, P.G., A.B. Sedman, C.E. Nugent, and M. Barr (1993) Angiotensin-converting enzyme inhibitor fetopathy. J. Am. Soc. Nephrol., $3: 1575-1582$

Ravid, M., H. Savin, I. Jutrin, T. Bental, B. Katz, and M. Lishner (1993) Long-term stabilizing effect of angiotensin-converting enzyme inhibition on plasma creatinine and on proteinuria in normotensive type-II diabetic patients. Ann. Int. Med. 118:577-581.

Restaino, I., B.S. Kaplan, P. Kaplan, H.K. Rosenberg, C. Witzleben, and N. Roberts (1991) Renal dysgenesis in a monozygotic twin: Association with in utero exposure to indomethacin. Am. J. Med. Genet., 39:252-257.

Rigat, B., C. Hubert, F. Alhenc-Gelas, F. Cambien, P. Corvol, and F. Soubrier (1990) An insertion deletion polymorphism in angiotensin I converting enzyme gene accounting for half the variance of serum enzyme levels. J. Clin. Invest., 86:1343-1346.

Robertson, R.T., D.H. Minsker, and D.L. Bokelman (1986) MK-421 (enalapril maleate): Late gestation and lactation study in rats. Jpn. Pharmacol. Ther., 14:43-55.

Rodicio, J.L., and L.M. Ruilope (1993) Angiotensin-converting enzyme inhibitors in the treatment of mild arterial hypertension. Clin. Exp. Hypertens., 15:1277-1289.

Rosa, F.W., L.A. Bosco, C. Fossum-Graham, J.B. Milstien, M. Dreis, and J. Creamer (1989) Neonatal anuria with maternal angiotensinconverting enzyme inhibition. Obstet. Gynecol., 74:371-374.
Rothberg, A.D., and R. Lorenz (1984) Can captopril cause fetal and neonatal renal failure? Pediatr. Pharmacol., 4:189-192.

Rudolph, A.M., M.A. Heyman, K.A.W. Teramo, C.T. Barrett, and N.C.R. Raiha (1971) Study on the circulation of the previable human fetus. Pediatr. Res., 5:452-465.

Sassano, P., G. Chatellier, E. Billaud, F. Alhenc-Gelas, P. Corvol, and J. Ménard (1987) Treatment of mild to moderate hypertension with or without the converting enzyme inhibitor enalapril: Results of a six-month double-blind trial. Am. J. Med., 83:227-235.

Schlueter, W., T. Keilani, and D.C. Batlle (1994) Tissue renin angiotensin systems: Theoretical implications for the development of hyperkalemia using angiotensin-converting enzyme inhibitors. Am. J. Med. Sci., 307(Suppl. 1):S81-S86.

Schubiger, G., G. Flury, and J. Nussberger (1988) Enalapril for pregnancy-induced hypertension: Acute renal failure in the neonate. Ann. Int. Med., 108:215-216.

Scott, A.A., and D.M. Purohit (1989) Neonatal renal failure: A complication of maternal antihypertensive therapy. Am. J. Obstet. Gynecol., 160:1223-1224.

Shanmugam, S., C. Monnot, P. Corvol, and J.M. Gasc (1994) Distribution of type 1 angiotensin II receptor subtype messenger RNAs in the rat fetus. Hypertension, 23:137-141

Simeoni, U., J. Messer, P. Weisburd, J. Haddad, and D. Willard (1989) Neonatal renal dysfunction and intrauterine exposure to prostaglandin synthesis inhibitors. Eur. J. Pediatr., 148:371-373.

Tack, E.D., and J.M. Perlman (1988) Renal failure in sick hypertensive premature infants receiving captopril therapy. J. Pediatr., 112: $805-810$.

Thorpe-Beeston, J.G., N.A. Armar, M. Dancy, G.W. Cochrane, G. Ryan, and C.H. Rodeck (1993) Pregnancy and ACE inhibitors. Br. J. Obstet. Gynaecol., 100:692-693.

Thurston, H. (1992) Angiatensin-converting enzyme inhibition as 1stline treatment for hypertension. Clin. Exp. Pharmacol. Physiol., Suppl. 19:67-71.

Todd, P.A., and R.C. Heel (1986) Enalapril: A review of its pharmacodynamic properties, and therapeutic use in hypertension and congestive heart failure. Drugs, 31:198-248.

Vanhoutte, P.M., C.M. Boulanger, S.C. Illiano, T. Nagao, M. Vidal, and J.V. Mombouli (1993) Endothelium-dependent effects of converting-enzyme inhibitors. J. Cardiovasc. Pharmacol., 22(Suppl.5): S10-S16.

Viberti, G., C.E. Mogensen, L.C. Groop, et al. (1994) Effect of captopril on progression to clinical proteinuria in patients with insulin-dependent diabetes-mellitus and microalbuminuria. JAMA, 271:275279 .

Vidt, D.G., E.L. Bravo, and F.M. Fouad (1982) Captopril. N. Engl. J. Med., 306:214-219.

Voyer, L.E., R. Drut, and J.H. Mendez (1994) Fetal renal maldevelopment with oligohydramnios following maternal use of piroxicam. Pediatr. Nephrol., 8:592-594.

Wells, T.G., T.E. Bunchman, and G.L. Kearns (1990) Treatment of neonatal hypertension with enalapril. J. Pediatr., 117:664-667.

Williams, G.H. (1988) Converting enzyme inhibitors in the treatment of hypertension. N. Engl. J. Med., 319:1517-1524.

Wood, E.G., T.E. Bunchman, and R.F. Lynch (1991) Captopril-induced reversible acute renal failure in an infant with coarctation of the aorta. Pediatrics, 88:816-818.

Yosipiv, I.V., S. Dipp, and S.S. Eldahr (1994) Ontogeny of somatic angiotensin-converting enzyme. Hypertension, 23:369-374. 